\title{
Mechanical, pH and Thermal Stability of Mesoporous Hydroxyapatite
}

\author{
Joanna Kamieniak $^{1} \cdot$ Peter J. Kelly $^{1} \cdot$ Craig E. Banks $^{1} \cdot$ Aidan M. Doyle $^{1}$
}

Received: 13 July 2017 / Accepted: 14 August 2017 / Published online: 11 October 2017

(c) The Author(s) 2017. This article is an open access publication

\begin{abstract}
The stability of mesoporous hydroxyapatite (HAP) powder was studied following treatments of ultrasound, $\mathrm{pH}$ and heating. HAP was found to be mechanically stable up to (and including) $1 \mathrm{~h}$ continuous ultrasonic treatment in water. The HAP structure was also stable to $\mathrm{pH}$, evidenced by practically identical XRD and FTIR spectra over the $\mathrm{pH}$ range $2-12$. The surface area increased progressively with increasing acidity, reaching a maximum of $121.9 \mathrm{~m}^{2} \mathrm{~g}^{-1}$ at $\mathrm{pH} 2$, while alkaline conditions decreased the surface area to a minimum of $55.4 \mathrm{~m}^{2} \mathrm{~g}^{-1}$ at $\mathrm{pH} 12$. Heating in air had a significant influence on the structural and morphological properties of HAP, which underwent dehydroxylation to form oxyhydroxyapatite (OHAP) at temperatures $\geq 650^{\circ} \mathrm{C}$, and $\beta$-tricalcium phosphate ( $\beta$-TCP) $\geq 750{ }^{\circ} \mathrm{C}$. The surface area decreased at elevated temperatures due to agglomeration of HAP crystals by sintering, which was associated with an increased particle size.
\end{abstract}

Keywords Hydroxyapatite $\cdot$ Mesoporous $\cdot$ Surface area $\cdot$ Stability $\cdot$ Dehydroxylation

Electronic supplementary material The online version of this article (doi:10.1007/s10904-017-0652-3) contains supplementary material, which is available to authorized users.

Craig E. Banks

c.banks@mmu.ac.uk

Aidan M. Doyle

a.m.doyle@mmu.ac.uk

1 Faculty of Science and Engineering, Manchester Metropolitan University, Chester Street, Manchester M1 5GD, UK

\section{Introduction}

Hydroxyapatite $\left[\mathrm{Ca}_{10}\left(\mathrm{PO}_{4}\right)_{6}(\mathrm{OH})_{2}, \mathrm{HAP}\right]$ is a stable apatite compound and has been used widely due to its similarity to human bone composition, biocompatibility and bioactivity [1]. Synthetic HAP is employed as a biomaterial for orthopaedic and dental replacements [2]. Beside medical applications it has been also applied in the field of heterogeneous catalysis as a support because of its bifunctionality, hydrophilic properties and high structural stability, as reviewed by Gruselle et al. [3]. HAP can also be applied in other fields, such as purification of wastewater, detection of heavy metals in water [4, 5], environmental pollution control [6] and electrochemical applications [7]. The most common form of HAP is the hexagonal crystal structure, $\mathrm{P}_{3} / \mathrm{m}$ space group, with $\mathrm{Ca} / \mathrm{P}$ ratio 1.67 [8]. The most widely employed method to synthesise HAP is by wet chemical precipitation [9-11]. Alternative techniques are sol-gel [12], hydrothermal [13] or other protocols that involve microwave irradiations [14], spray pyrolysis [15] or emulsion processing [16]. A number of factors influence the precipitation of HAP, such as stoichiometry, $\mathrm{pH}$, temperature and rate of reagent addition; it is therefore crucial to control these aspects to produce HAP with an optimum morphology and crystallinity [17].

The stability of HAP affects its solubility, biocompatibility and resorption rate influencing the performance as a bio-implant in living systems [18]. Dehydroxylation of $\mathrm{HAP}$ at high temperatures, leading to loss of the $\mathrm{OH}^{-}$group, can negatively influence the activity of HAP as a catalyst support [19]. In consequence, several compounds can be formed such as oxyapatite (OAP), oxyhydroxyapatite (OHAP), $\beta$-tricalcium phosphate ( $\beta$-TCP), calcium oxide and tetracalcium phosphate (TTCP) [20, 21]. Dehydroxylation is accelerated by increased deficiency of calcium ions in HAP and occurs at $500{ }^{\circ} \mathrm{C}$, as described by Raynaud et al. 
[22]. Other studies focused on the mechanical stability of HAP scaffolds for bio-medical applications. For example Gervaso et al. [23]. described the mechanical stability of the previously synthesised scaffolds using compression in simulated body fluid (SBF) and tris-HCl buffer finding that after 28 days the stress at failure was $0.57 \mathrm{MPa}$, which was only slightly different to samples before soaking, $0.51 \mathrm{MPa}$ [23]. An understanding of the chemical stability of HAP is required for many applications. For example, Sun et. al [21]. reported the influence of $\mathrm{pH}$ (during synthesis) on the properties of HAP, showing the formation of octacalcium phosphate (OCP) at low $\mathrm{pH}$, while HAP is present at higher $\mathrm{pH}$ and temperatures [21].

We recently reported the successful preparation of mesporous HAP and its application as a heterogeneous catalyst support in the decomposition of methane in natural gas-diesel engine exhaust emissions [24, 25]. Here, we investigate the stability of this mesoporous HAP by testing its resistance to ultrasonic treatment, $\mathrm{pH}$ and temperature. The results show that the HAP structure is mechanically robust, fully resistant to changes in $\mathrm{pH}$, and stable upon heating in air to approximately $650{ }^{\circ} \mathrm{C}$. These findings support the use of HAP in a range of applications.

\section{Experimental}

\subsection{Materials and Chemicals}

All chemicals: calcium nitrate tetrahydrate $(>99 \%)$, potassium phosphate monobasic ( $>99 \%)$, nitric acid $70 \%(\mathrm{v} / \mathrm{v})$, polyoxyethylene(20) sorbitan monostearate $\left(10 \%\right.$ in $\left.\mathrm{H}_{2} \mathrm{O}\right)$, nonaoxyethylene dodecyl ether, sodium hydroxide pellets (>98\%), ethanol (98\%), phosphoric acid $85 \%(\mathrm{v} / \mathrm{v})$, boric acid $(99.5 \%)$, ethanoic acid $>99 \%(\mathrm{v} / \mathrm{v})$ were obtained from Sigma-Aldrich and used as received without any further purification. All solutions were made using deionised water with resistivity not less than $18.2 \mathrm{M} \Omega \mathrm{cm}$.

\subsection{Synthesis of Hydroxyapatite}

Hydroxyapatite (HAP) synthesis was based on a method reported elsewhere [26]. $\mathrm{Ca}\left(\mathrm{NO}_{3}\right)_{2}(7.88 \mathrm{~g})$ was mixed with $\mathrm{KH}_{2} \mathrm{PO}_{4}(2.72 \mathrm{~g})$, dissolved in deionised water $(26.60 \mathrm{~mL})$ and acidified by concentrated $\mathrm{HNO}_{3}(13.60 \mathrm{~mL})$ to avoid precipitation of $\mathrm{Ca}_{3}\left(\mathrm{PO}_{4}\right)_{2}$. This acidic solution was then added to a mixture of polyoxyethylene(20) sorbitan monostearate (Tween 60, $26 \mathrm{~g}$ ) and nonaoxyethylene dodecyl
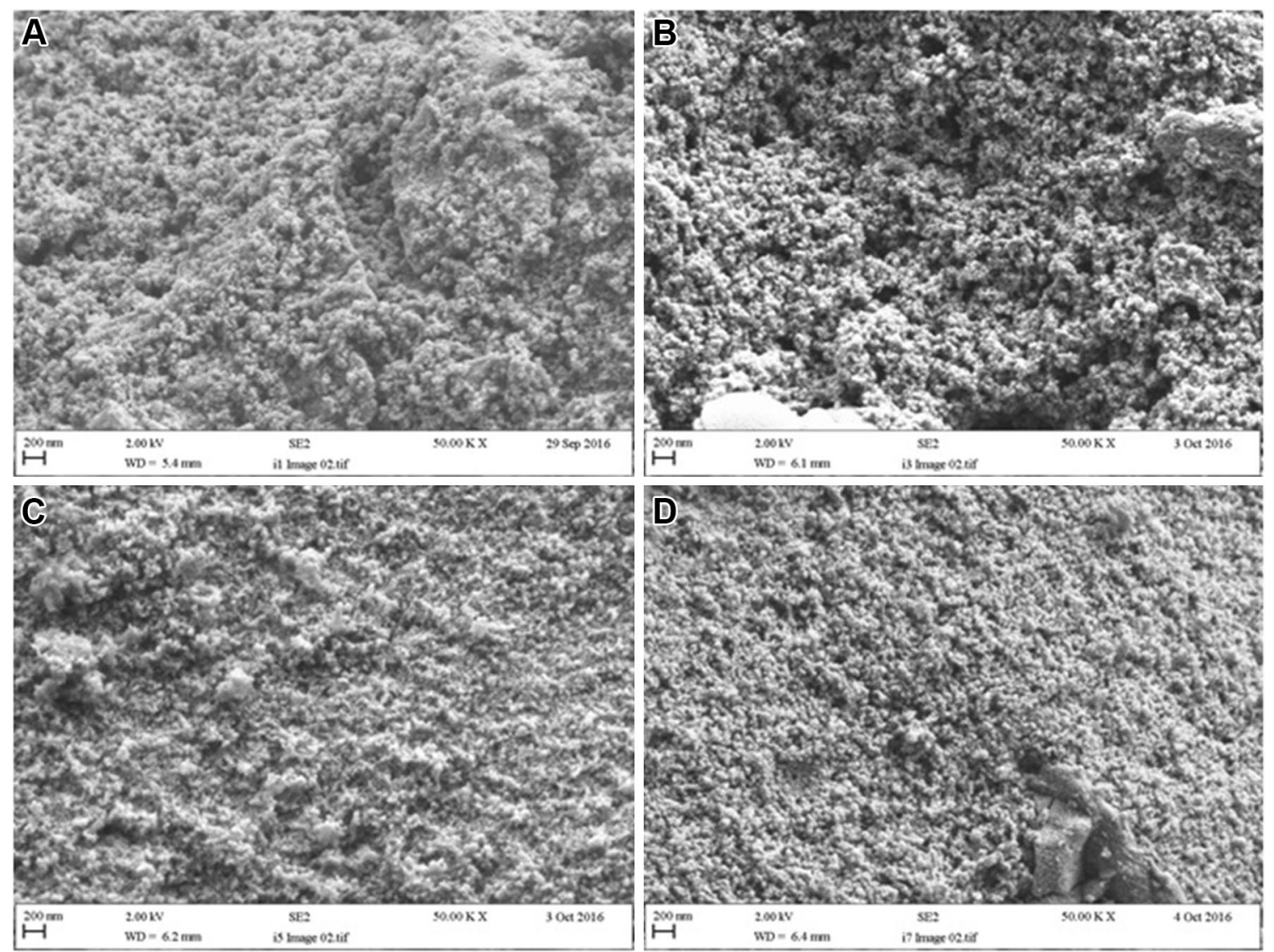

Fig. 1 SEM images of ultrasound treated HAP: as-synthesised (a); $20 \mathrm{mins} \mathrm{(b);} 40 \mathrm{~min}$ (c); $60 \mathrm{~min}$ (d) 

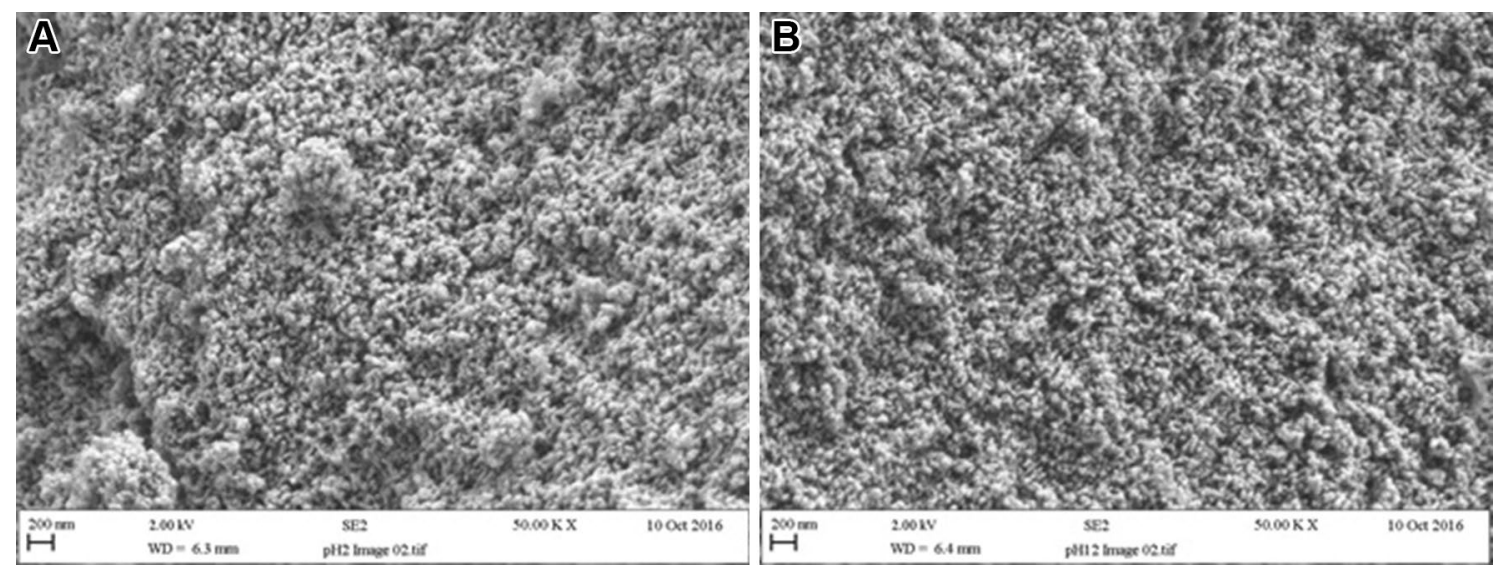

Fig. 2 SEM images of HAP treated in buffer pH 2 (a) and pH 12 (b)

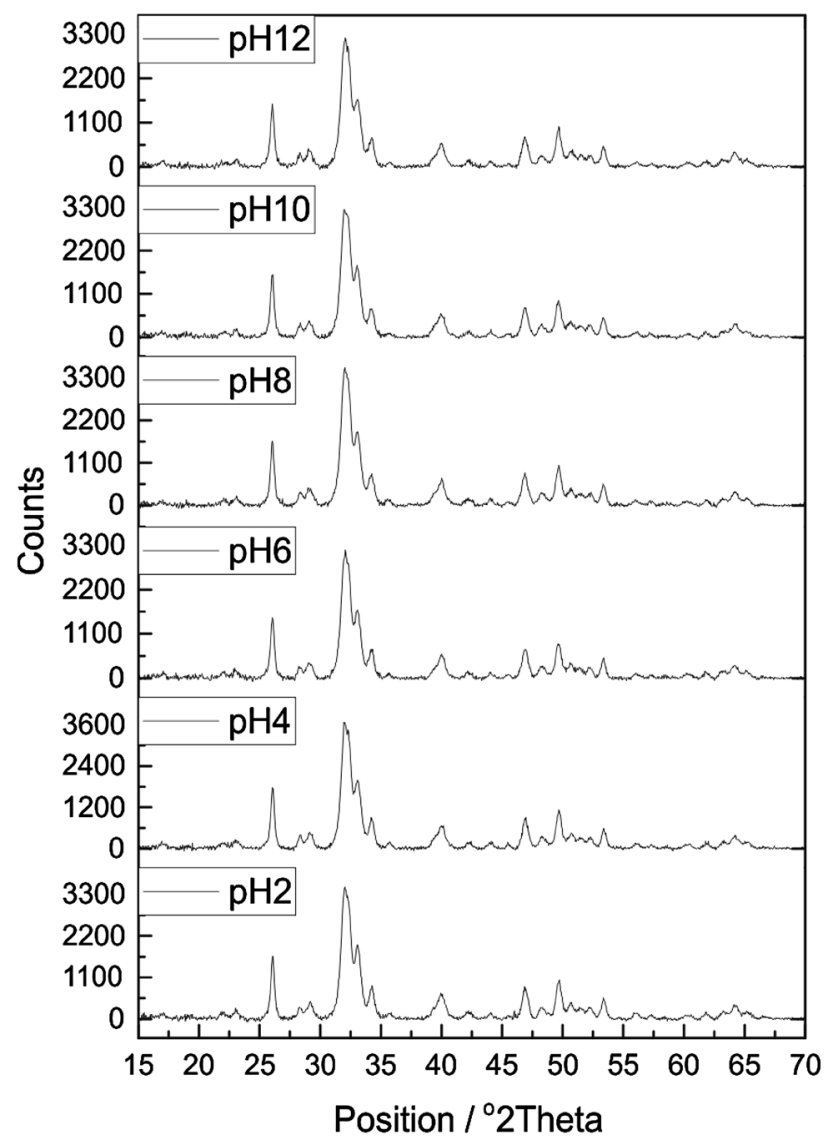

Fig. 3 XRD powder patterns of HAP in $\mathrm{pH}$ buffer

ether $\left(\mathrm{C}_{12} \mathrm{EO}_{9}, 10.66 \mathrm{~g}\right)$, and heated to $60{ }^{\circ} \mathrm{C}$ with stirring until a clear solution was formed. The solution was cooled to room temperature and treated with $\mathrm{NaOH}(0.2 \mathrm{M})$ added dropwise to maintain a stable $\mathrm{pH}$ of 9.8 to precipitate HAP. The suspension was stirred overnight, filtered, washed with ethanol and water, dried at $60{ }^{\circ} \mathrm{C}$ in air and calcined in air for $5 \mathrm{~h}$ at $550{ }^{\circ} \mathrm{C}$ with a heating rate $10{ }^{\circ} \mathrm{C} \mathrm{min}^{-1}$.

\subsection{Mechanical Testing}

HAP $(0.1 \mathrm{~g})$ was mixed with deionised water $(1 \mathrm{~mL})$ in a volumetric flask. Mixtures were placed in an ultrasonic bath (Ultrawave Limited, Cardiff, UK) for durations from $10 \mathrm{~min}$ to $1 \mathrm{~h}$. A sample of HAP was left without any ultrasonic treatment as a control. All samples were recovered by filtration and dried at $60{ }^{\circ} \mathrm{C}$ in air.

\section{4 pH Stability}

HAP $(0.3 \mathrm{~g})$ was added to Britton-Robinson buffer solutions $(20 \mathrm{~mL})$. Different $\mathrm{pH}(2,4,6,8,10,12)$ buffers were prepared using $\mathrm{NaOH}(0.2 \mathrm{M})$. The mixtures were stirred for $3 \mathrm{~h}$ under ambient conditions, the solid was recovered by filtration and dried at $60^{\circ} \mathrm{C}$ in air.

\subsection{Thermal Stability}

HAP $(0.3 \mathrm{~g})$ samples were placed in crucibles and heated in a furnace (OMEGALUX LMF-3550) to temperatures between 550 and $900{ }^{\circ} \mathrm{C}$ for $3 \mathrm{~h}$ in air with a heating rate $10{ }^{\circ} \mathrm{C} \mathrm{min}-1$. Each sample was cooled to room temperature prior to removal.

\subsection{Characterisation}

$\mathrm{X}$-ray diffraction (XRD) was conducted in powder spinning mode at ambient conditions using a Panalytical X'Pert Powder diffractometer with $\mathrm{Cu} \mathrm{K} \alpha$ radiation $(\lambda=1.5406 \AA)$. All powder diffraction patterns were recorded with step size 0.052 and step time $200 \mathrm{~s}$, using an X-ray tube operated at $40 \mathrm{kV}$ and $30 \mathrm{~mA}$ with fixed $1 / 2^{\circ}$ anti-scatter slit. Nitrogen 

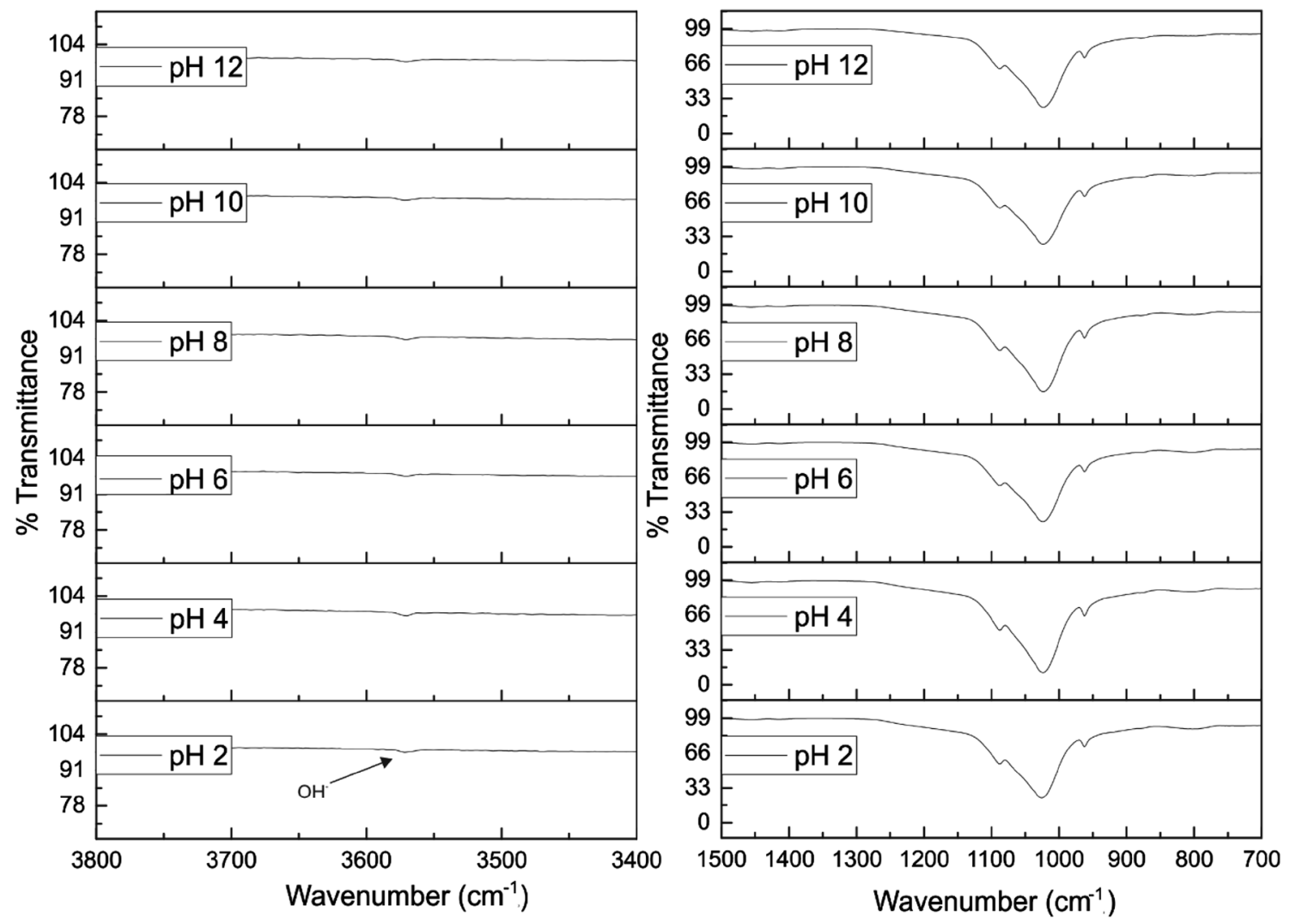

Fig. 4 FTIR spectra of HAP in pH buffer

Table 1 Nitrogen adsorption porosimetry data of HAP in $\mathrm{pH}$ buffer

\begin{tabular}{lc}
\hline $\mathrm{pH}$ & Surface area $\left(\mathrm{m}^{2} \mathrm{~g}^{-1}\right)$ \\
\hline As synthesised & $84.9 \pm 0.3$ \\
2 & $121.9 \pm 0.8$ \\
4 & $105.4 \pm 0.7$ \\
6 & $87.8 \pm 0.6$ \\
8 & $79.6 \pm 0.8$ \\
10 & $62.7 \pm 0.3$ \\
12 & $55.4 \pm 0.2$ \\
\hline
\end{tabular}

adsorption/desorption measurements were carried out using a Micromeritics ASAP 2020 Surface Analyser at $-196{ }^{\circ} \mathrm{C}$. Samples were degassed under vacuum $\left(\mathrm{p}<10^{-5} \mathrm{mbar}\right)$ for $3 \mathrm{~h}$ at $300{ }^{\circ} \mathrm{C}$ prior to analysis. Surface areas of the samples were calculated in the relative pressure range $0.05-0.30$ using the BET isotherm model; this is the accepted method of reporting surface areas. Microscopic images were recorded using a Supra 40VP (Carl Zeiss Ltd, UK) scanning electron microscope (SEM). Fourier transform infrared spectroscopy (FTIR) was conducted using a diamond source Nicolet 380 series, Thermo Electron Corporation.

\section{Results and Discussion}

\subsection{Mechanical Testing}

The SEM images in Fig. 1 clearly show that HAP is stable to $1 \mathrm{~h}$ continuous exposure to ultrasonic treatment. The surface areas of treated samples varied by less than $\pm 1 \%$ over the full range of ultrasound times used (data not shown). These data agree well with those reported in literature. For example, the mechanical stability of HAP scaffolds, prepared by a sponge replica method, was evaluated by a uniaxial compression test, which calculates the strength of HAP by measuring the stress value at failure. Results showed that the mechanical strength of this HAP was practically unchanged following 28 days' immersion in simulated body fluid [23]. HAP coatings deposited on titanium substrates were sufficiently strong that scratching with a diamond indenter was required to physically remove part of the HAP [27]. The fact that we do not observe any changes in HAP using the soft-templated preparation method proves that this HAP is particularly stable given the severity of $1 \mathrm{~h}$ ultrasonic treatment. Our findings support the use of HAP in applications where such materials' robustness and resistance to physical degradation are required. 

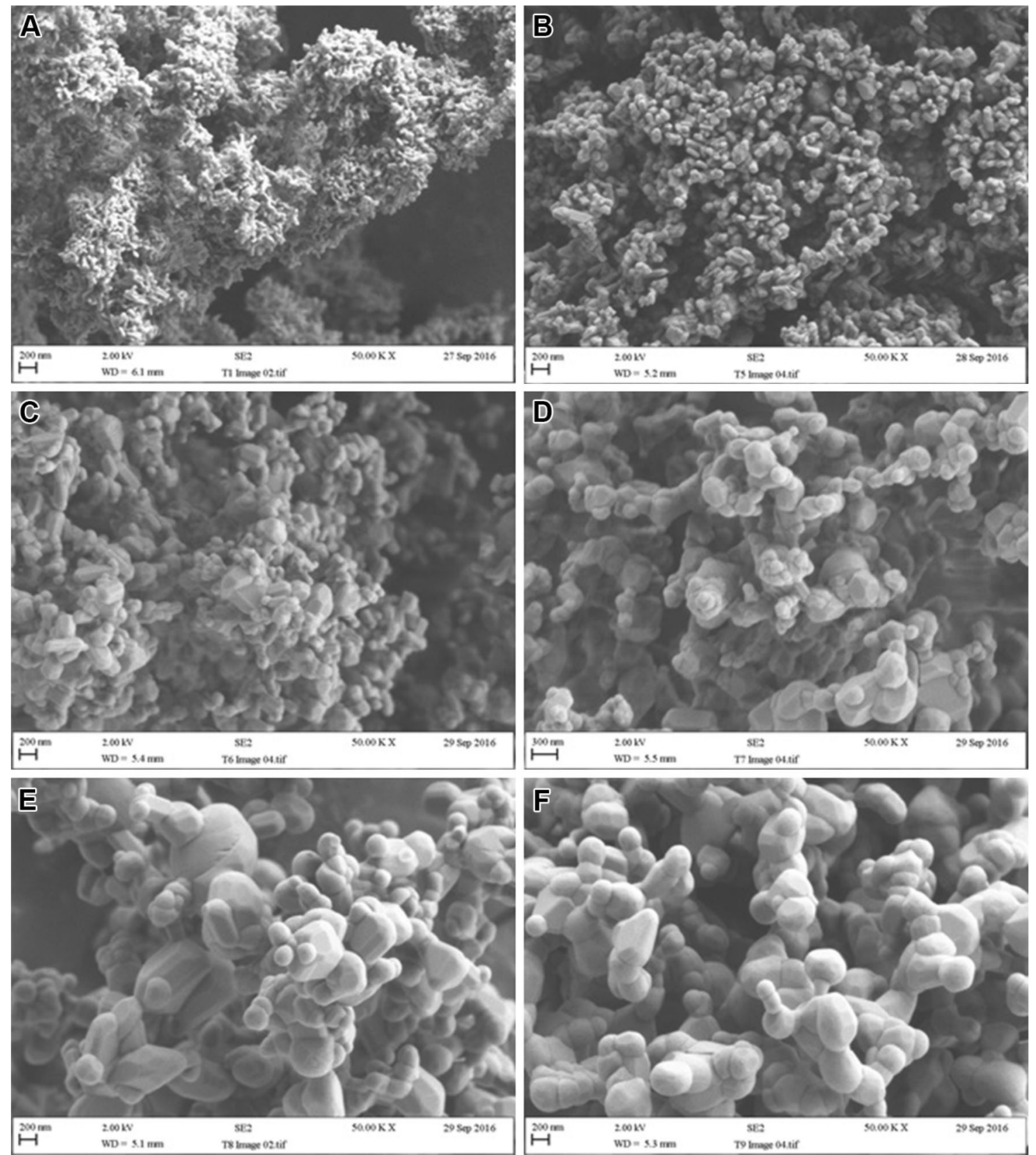

Fig. 5 SEM images as a function of treatment temperature; as synthesised $\mathrm{HAP}(\mathbf{a}) ; 700{ }^{\circ} \mathrm{C}(\mathbf{b}) ; 750{ }^{\circ} \mathrm{C}(\mathbf{c}) ; 800{ }^{\circ} \mathrm{C}(\mathbf{d}) ; 850{ }^{\circ} \mathrm{C}(\mathbf{e}) ; 900{ }^{\circ} \mathrm{C}(\mathbf{f})$

\section{2 pH Stability}

SEM images, Fig. 2, indicate that there are no detectable morphological changes to the HAP morphology in either acidic or alkaline conditions. The XRD powder patterns, Fig. 3, are identical across the full $\mathrm{pH}$ range 2-12, confirming that the hexagonally oriented HAP structure is unaffected by exposure to aqueous buffer solution over the full $\mathrm{pH}$ range. FTIR spectra, Fig. 4, identify the fundamental vibrational modes of HAP phosphate groups whereby the most intense peak at $1021 \mathrm{~cm}^{-1}$ and another peak at $1089 \mathrm{~cm}^{-1}$ are assigned to the $\mathrm{v}_{3} \mathrm{P}-\mathrm{O}$ stretching bond. The band at $962 \mathrm{~cm}^{-1}$ is attributed to the $\mathrm{v}_{1} \mathrm{P}-\mathrm{O}$ stretching bond and the relatively weak signal at $3568 \mathrm{~cm}^{-1}$ corresponds to the $\mathrm{OH}$ group [28]. Taken together with the SEM images and XRD patterns, the FTIR spectra provide further evidence of the stability of HAP to acid/alkaline solution by the presence of identical spectra over the entire $\mathrm{pH}$ range. It is well known that the properties of HAP are strongly affected by the $\mathrm{pH}$ of solutions used during synthesis. Sun et al. showed 
Table 2 Nitrogen adsorption porosimetry data of HAP as a function of treatment temperature

\begin{tabular}{ll}
\hline Temperature $\left({ }^{\circ} \mathrm{C}\right)$ & Surface area $\left(\mathrm{m}^{2} \mathrm{~g}^{-1}\right)$ \\
\hline As synthesised & $84.9 \pm 0.3$ \\
550 & $70.3 \pm 0.6$ \\
600 & $64.2 \pm 0.2$ \\
650 & $43.7 \pm 0.2$ \\
700 & $60.4 \pm 0.4$ \\
750 & $46.8 \pm 0.5$ \\
800 & $46.9 \pm 0.3$ \\
850 & $19.4 \pm 0.04$ \\
900 & $12.4 \pm 0.3$ \\
\hline
\end{tabular}

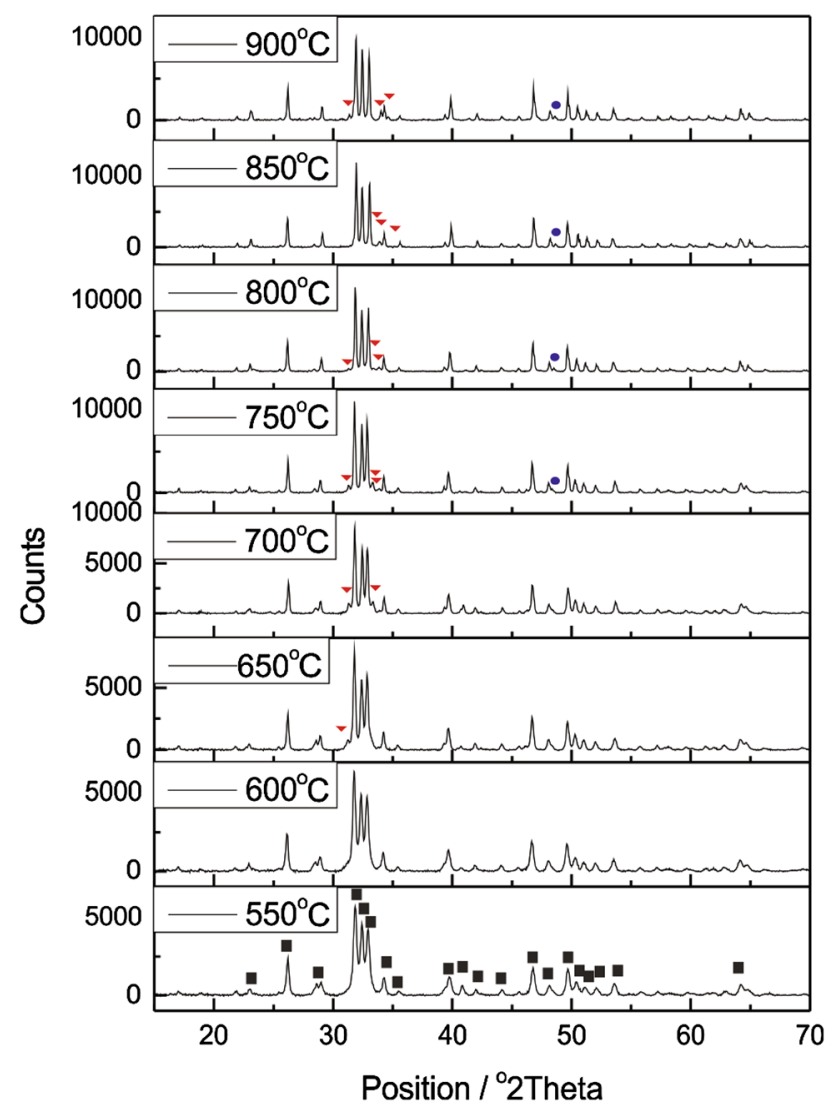

Fig. 6 XRD powder patterns of HAP as a function of treatment temperature: filled square HAP; filled inverted triangle OHAP; filled circle $\beta$-TCP. (Color figure online)

that the particle size and morphology of HAP prepared by hydrothermal treatment at $180{ }^{\circ} \mathrm{C}$ for $10 \mathrm{~h}$ varied as follows: $\mathrm{pH}$ 3.0, 3-D structured flower-like morphology; $\mathrm{pH}$ 5.0, 2-D nanoribbons diameter approximately $500 \mathrm{~nm} ; \mathrm{pH}$ 7.0, nanorods diameter approximately $20 \mathrm{~nm} ; \mathrm{pH} 11.0$, nanospheres [21]. Reports in the literature showing how $\mathrm{pH}$ affects the structural and morphological characteristics of post-synthesis HAP are lacking but, fortunately, it is possible to infer a comparison by examining the solubility product of HAP treated in acidic/alkaline solution. Larsen et al. showed that the solubility product of enamel apatite varied from 10 to 56.9 after exposure to $\mathrm{pH} 4.6$ for 60 days to $10^{-52.8}$ at $\mathrm{pH}$ 7.6. While the solubility product increases by a factor of approximately $10^{4}$, the absolute values of solubility product are extremely low across the $\mathrm{pH}$ scale i.e., HAP is practically insoluble. This suggests that any changes to the apatite structure due to dissolution into solution would be negligible, which is confirmed by the identical XRD spectra recorded for all samples from $\mathrm{pH} 4.6$ to 7.6 and the absence of any other calcium phosphate phases [29]. In another study, the solubility product of HAP (Ca:P ratio 1.664) was found to be constant over the $\mathrm{pH}$ range 4.56-9.67, although no XRD results were included [30].

It is interesting to note that the surface area of HAP increases in acidic media and decreases in basic media, Table 1. This may be a result of the higher concentrations of $\mathrm{OH}^{-}$ions at progressively higher $\mathrm{pH}$. Studies have shown that surface $\mathrm{OH}^{-}$ions are required for the crystallisation and growth of $\mathrm{Ca}_{5}\left(\mathrm{PO}_{4}\right)_{3} \mathrm{OH}$ [21]. It seems plausible that, in our study, the $\mathrm{OH}^{-}$ions remaining from the $\mathrm{pH}$ treatment may cause further reaction of the HAP during the heating step that precedes BET surface area analysis, which ultimately causes some agglomeration of particles with an associated reduction in surface area. The extent of this reaction increases with greater $\mathrm{pH}$ due to the increasing $\mathrm{OH}^{-}$concentration.

\subsection{Influence of Temperature}

Heating in air causes the transformation of rod like crystals, with well-defined edges, of the as synthesised HAP to larger agglomerated spherical particles; this effect is first detected at $700{ }^{\circ} \mathrm{C}$ and becomes increasingly more pronounced at higher temperatures, SEM images Fig. 5. This sintering of particles and the associated increase in particle size, and decrease in surface area Table 2, are typical of Ostwald ripening. Sun et al. showed that the particle size and shape of HAP were unchanged after heating to $600{ }^{\circ} \mathrm{C}$ but the HAP building units sintered together on heating at $800{ }^{\circ} \mathrm{C}$ [21]. In another study, heat treatment of HAP coatings to $700{ }^{\circ} \mathrm{C}$ in dry air caused the edges of the crystals to become more rounded, while heating to $900{ }^{\circ} \mathrm{C}$ in the same conditions resulted in crystals being fully covered with smaller crystal grains [20] The crystallinity was examined by XRD. As shown in Fig. 6, the diffraction peaks become more intense with temperature, implying an improvement in HAP crystallinity (see XRD pattern of untreated HAP, ESI Fig. 1, as a comparison). While the HAP crystal structure is present over the entire temperature range, there is partial transformation/decomposition of the HAP phase that becomes more 

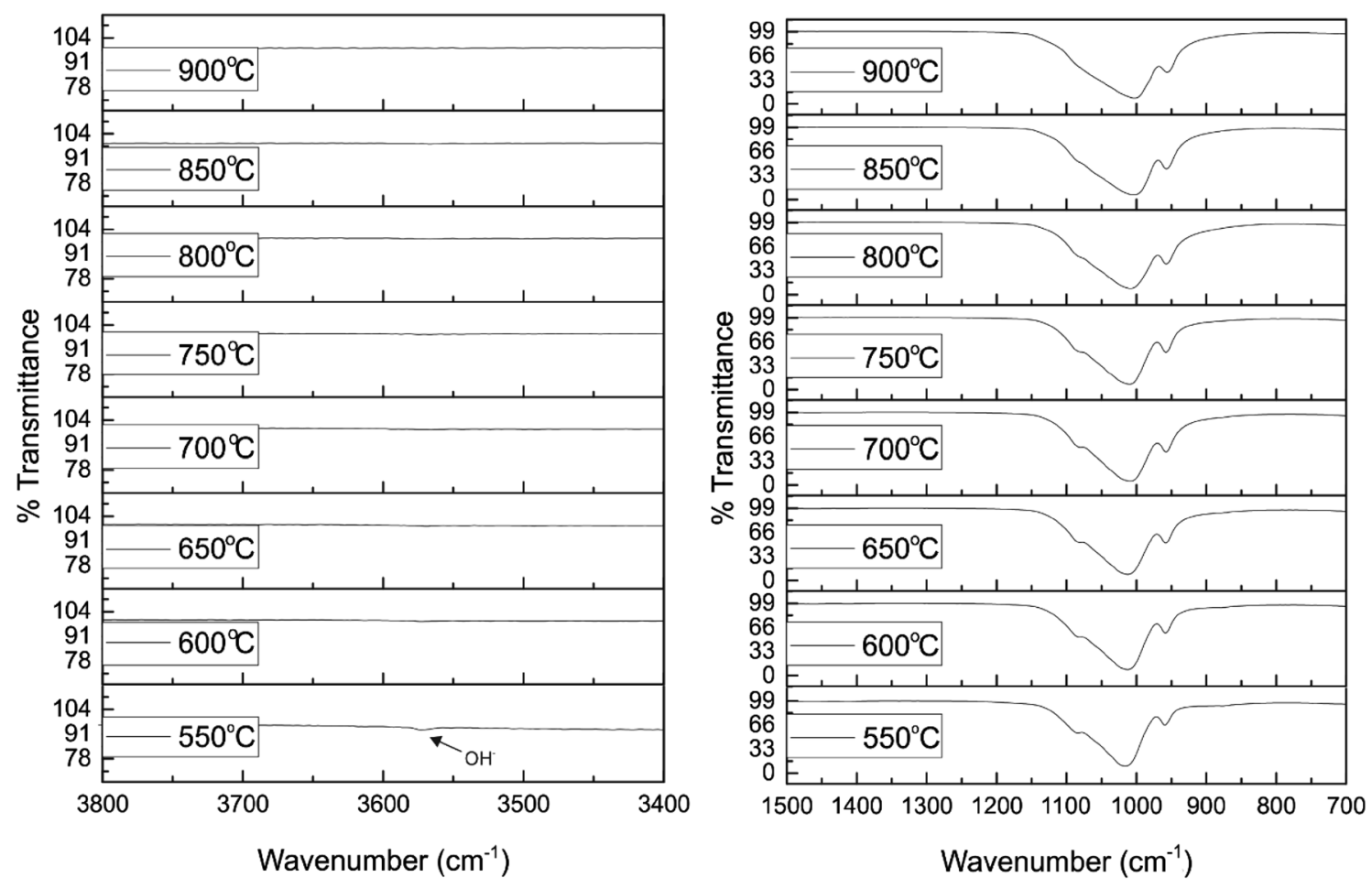

Fig. 7 FTIR spectra of HAP as a function of treatment temperature

pronounced with increased temperature. HAP is known to undergo dehydroxylation to oxyhydroxyapatite (OHAP), and to transform into several calcium phosphates, such as TTCP or $\beta$-TCP, as described by Rapacz-Kmita et al. [18]. In the present study, HAP dehydroxylation starts at $650{ }^{\circ} \mathrm{C}$ with further decomposition to $\beta$-TCP from $750{ }^{\circ} \mathrm{C}$. The dehydroxylation and decomposition reactions of HAP can be distinguished using FTIR. As observed in Fig. 7 (right), the $\mathrm{P}-\mathrm{O}$ vibration band at $1082 \mathrm{~cm}^{-1}$ becomes broader as the temperature increases, suggesting the transformation of HAP to $\beta$-TCP [28]. According to the report by Savino et al., [20] where HAP was electrochemically functionalised with fluoride to increase thermal resistance of the material, unmodified HAP decomposed to $\beta$-TCP at $600{ }^{\circ} \mathrm{C}$, which is lower than that reported in this manuscript. The weak $\mathrm{O}-\mathrm{H}$ band at $3567 \mathrm{~cm}^{-1}$ disappears due to the dehydroxylation process and subsequent formation of OHAP (Fig. 6 left). It is noteworthy that there are two small vibration bands at 1455 and $1412 \mathrm{~cm}^{-1}$ that correspond to $\mathrm{v}_{3} \mathrm{CO}_{3}{ }^{2-}$ adsorbed from the air onto the surface of HAP, diminishing at higher temperatures showing that the carbonate ion is released $[31,32]$.

\section{Conclusions}

Mesoporous HAP was successfully synthesised by a mixed surfactant, soft-templated approach. Studies proved that the crystal structure and morphology of mesoporous HAP are unaffected by ultrasonic treatment or exposure to $\mathrm{pH}$ in the range 2-12. HAP was stable to heating in air to approximately $650{ }^{\circ} \mathrm{C}$, while higher temperatures caused partial decomposition of the HAP structure, reduced surface area and increased particle size.

Acknowledgements The authors are grateful to G-volution plc. for their support and contributions to this research.

Open Access This article is distributed under the terms of the Creative Commons Attribution 4.0 International License (http://creativecommons.org/licenses/by/4.0/), which permits unrestricted use, distribution, and reproduction in any medium, provided you give appropriate credit to the original author(s) and the source, provide a link to the Creative Commons license, and indicate if changes were made.

\section{References}

1. Y.-H. Yang, C.-H. Liu, Y.-H. Liang, F.-H. Lin, K.C.W. Wu, J. Mater. Chem. B 1, 2447 (2013). doi:10.1039/C3TB20365D

2. D. Bellucci, A. Sola, M. Gazzarri, F. Chiellini, V. Cannillo, Mater. Sci. Eng. C 33, 1091 (2013). doi:10.1016/j.msec.2012.11.038

3. M. Gruselle, J. Organomet. Chem. 793, 93 (2015). doi:10.1016/j. jorganchem.2015.01.018

4. N. Gupta, A.K. Kushwaha, M.C. Chattopadhyaya, J. Taiwan Inst. Chem. Eng. 43, 125 (2012). doi:10.1016/j.jtice.2011.07.009 
5. T.A. Salah, A.M. Mohammad, M.A. Hassan, B.E. El-Anadouli, J. Taiwan Inst. Chem. Eng. 45,, 1571 (2014). doi:10.1016/j. jtice.2013.10.008

6. M. Kemiha, D.P. Minh, N. Lyczko, A. Nzihou, P. Sharrock, Procedia Eng. 83, 394 (2014). doi:10.1016/j.proeng.2014.09.044

7. P. Kanchana, C. Sekar, Mater. Sci. Eng. C 42, 601 (2014). doi:10.1016/j.msec.2014.05.072

8. S. Meejoo, W. Maneeprakorn, P. Winotai, Thermochim. Acta 447, 115 (2006). doi:10.1016/j.tca.2006.04.013

9. A. Andrasekhar, S. Sagadevan, A. Dakshnamoorthy, Int. J. Phys. Sci. 8, 1639 (2013)

10. P. Wang, C. Li, H. Gong, X. Jiang, H. Wang, K. Li, Powder Technol. 203, 315 (2010). doi:10.1016/j.powtec.2010.05.023

11. P. Kamalanathan, S. Ramesh, L.T. Bang et al., Ceram. Int. 40, 16349 (2014). doi:10.1016/j.ceramint.2014.07.074

12. Y. Feng, H. Yin, D. Gao, A. Wang, L. Shen, M. Meng, J. Catal. 316, 67 (2014). doi:10.1016/j.jcat.2014.04.020

13. S.-C. Wu, H.-K. Tsou, H.-C. Hsu, S.-K. Hsu, S.-P. Liou, W.-F. Ho, Ceram. Int. 39, 8183 (2013). doi:10.1016/j.ceramint.2013.03.094

14. J. Liu, K. Li, H. Wang, M. Zhu, H. Yan, Chem. Phys. Lett. 396, 429 (2004). doi:10.1016/j.cplett.2004.08.094

15. J.S. Cho, S.-H. Rhee, J. Eur. Ceram. Soc. 33, 233 (2013). doi:10.1016/j.jeurceramsoc.2012.08.029

16. C.-W. Chen, R.E. Riman, K.S. TenHuisen, K. Brown, J. Cryst. Growth 270, 615 (2004). doi:10.1016/j.jcrysgro.2004.06.051

17. P.N. Kumta, C. Sfeir, D.-H. Lee, D. Olton, D. Choi, Acta Biomater. 1, 65 (2005). doi:10.1016/j.actbio.2004.09.008

18. A. Rapacz-Kmita, C. Paluszkiewicz, A. Ślósarczyk, Z. Paszkiewicz, J. Mol. Struct. 744-747, 653 (2005). doi:10.1016/j. molstruc.2004.11.070

19. Z. Boukha, J.L. Ayastuy, J.R. González-Velasco, M.A. Gutiérrez-Ortiz, Appl. Catal., B 201, 189 (2017). doi:10.1016/j. apcatb.2016.08.039
20. K. Savino, M.Z. Yates, Ceram. Int. 41, 8568 (2015). doi:10.1016/j. ceramint.2015.03.065

21. R. Sun, K. Chen, Z. Liao, N. Meng, Mater. Res. Bull. 48, 1143 (2013). doi:10.1016/j.materresbull.2012.12.013

22. S. Raynaud, E. Champion, D. Bernache-Assollant, P. Thomas, Biomaterials 23, 1065 (2002). doi:10.1016/S0142-9612(01)00218-6

23. F. Gervaso, S.K. Padmanabhan, F. Scalera, A. Sannino, A. Licciulli, Mater. Lett. 185, 239 (2016). doi:10.1016/j. matlet.2016.08.139

24. J. Kamieniak, E. Bernalte, C. Foster, A. Doyle, P. Kelly, C. Banks, Catalysts 6, 119 (2016)

25. J. Kamieniak, E. Bernalte, A.M. Doyle, P.J. Kelly, C.E. Banks, Catal. Lett. 147, 2200 (2017)

26. M. Uota, H. Arakawa, N. Kitamura, T. Yoshimura, J. Tanaka, T Kijima, Langmuir 21, 4724 (2005). doi:10.1021/la050029m

27. A.V. Zavgorodniy, O. Borrero-López, M. Hoffman, R.Z. LeGeros, R. Rohanizadeh, J. Biomed. Mater. Res. B 99B, 58 (2011). doi:10.1002/jbm.b.31872

28. S. Kannan, J.M.F. Ferreira, Chem. Mater. 18, 198 (2006). doi:10.1021/cm051966i

29. M.J. Larsen, S.J. Jensen, Arch. Oral Biol. 34, 957 (1989). doi:10.1016/0003-9969(89)90052-6

30. L.C. Bell, H. Mika, B.J. Kruger, Arch. Oral Biol. 23, 329. doi:10.1016/0003-9969(78)90089-4

31. R.C. Moore, M.J. Rigali, P. Brady, Environ. Pollut. 218, 1102 (2016). doi:10.1016/j.envpol.2016.08.063

32. B.K. Sarma, P. Barman, B. Sarma, A. Das, A.R. Pal, Mater. Lett. 185, 387 (2016). doi:10.1016/j.matlet.2016.09.028 